\title{
Development of an innovative interlocking load bearing hollow block system in Malaysia
}

\begin{abstract}
The paper describes the development of a new interlocking hollow block masonry system appropriate for load bearing masonry wall construction. The developed system is an alternative to the traditional bonded masonry system where the blocks in the wall are integrated through mortar layers. In the system developed, the blocks are stacked on one another and three-dimensional interlocking protrusions are provided in the blocks to integrate the blocks into walls. This paper includes the background, concept and procedure used to develop an efficient interlocking hollow block system, which may be used in the construction of load bearing walls. Twenty-one different block models have been investigated and analysed with respect to weight, bearing and shear areas, shape, ease of production, ability to accommodate vertical and horizontal reinforcing stabilising ties and efficiency of the interlocking mechanism under imposed loads. The blocks, developed under the name 'PUTRA BLOCK', have been used to construct a single-storey house at Universiti Putra Malaysia. The system provides a fast, easy and an accurate building system.
\end{abstract}

Keyword: Masonry system, Putra block, Interlocking load bearing hollow block, Dry construction, Modular coordination 